Morrigan, B., Keesing, S., \& Breen, L. J. (2020). Exploring the social networks of bereaved spouses: Phenomenological case studies. Omega: Journal of Death and Dying. Copyright (C) 2020 Sage. https://doi.org/10.1177/0030222820944062.

\title{
Exploring the Social Networks of Bereaved Spouses: Phenomenological Case Studies
}

\author{
Brigid Morrigan $^{1}$ \\ Sharon Keesing ${ }^{2}$ \\ Lauren J. Breen ${ }^{1}$
}

${ }^{1}$ School of Psychology, Curtin University, Perth, Western Australia, Australia

${ }^{2}$ School of Occupational Therapy, Social Work and Speech Pathology, Curtin University,

Perth, Western Australia, Australia

Correspondence concerning this article should be addressed to Dr. Lauren J. Breen, School of Psychology, Curtin University, GPO Box U1987, Perth Western Australia 6845, Australia. Email lauren.breen@curtin.edu.au 


\begin{abstract}
Bereavement is a significant stressor that can affect and be affected by social support, yet there is little known about the social networks of bereaved individuals. We conducted an indepth qualitative examination of the social networks of bereaved spouses through an interpretive phenomenological analysis. Five participants were interviewed about their social networks prior to and following bereavement. Participants described considerable changes in their social networks. They reported connecting with others who had experienced similar stressors, including via online support groups for widows/widowers, as a key strategy for reengagement with their social worlds. The death of a spouse can precipitate the dramatic reorganization of social networks to incorporate and adapt to this crisis. Findings offer guidance for service providers to support bereaved spouses to harness existing social networks to optimize received support.
\end{abstract}

Keywords: Spousal bereavement, widows, widowers, social support, social networks, phenomenology 


\section{Exploring the Social Networks of Bereaved Spouses: Phenomenological Case Studies}

The death of a spouse is a significant life stressor and a common human experience (Center for the Advancement of Health, 2004). The experience of grief that occurs for each person as they navigate bereavement is unique and depends upon the characteristics of the bereaved person, the circumstances of the death, and the broader context in which the loss occurs (Blackburn, \& Dwyer, 2017; Burke \& Neimeyer, 2013; Lobb, Kristjanson, Aoun, Monterosso, Halkett, \& Davies, 2010). Social support is one such factor that can be modified after bereavement, yet has received limited research attention, due to the focus on individual and psychological phenomena at the expense of social and sociological contexts (Breen et al., 2019; Breen, Kawashima et al., 2020; Thompson et al., 2016). A recent systematic review provided a comprehensive investigation of studies on the factors that determine the provision of social support and the authors highlighted that the methodological flaws and fragmentation impeded the translation of research into practical strategies (Logan, Thornton, \& Breen, 2018).

Social networks comprise people and organizations within which an individual is embedded and through which an individual will both provide and receive support (Kaunonen, Tarkka, Paunonen, \& Laippala, 1999; Schnittger, Wherton, Prendergast, \& Lawlor, 2012). Bronfenbrenner (1977) described social interaction within an ecological model comprising close interactions with family members, close friends, and closely-related community organizations, which provide the most intimate level of interaction. This microsystem is surrounded by broader, nested levels of external influence with the wider community, professional or government bodies, and social and cultural values. The microsystem encompasses those intimate relationships with close family and friends and the instrumental assistance of community groups (Bronfenbrenner, 1977); it is these relationships that form social networks. 
The provision of support from a social network involves several processes-a potential supporter must recognize a need for support, the potential supporter must have the capacity and willingness to provide support, and the support provided must be perceived by its receiver as supportive (Aoun, Breen, White, Rumbold, \& Kellehear, 2018; Kaunonen, Tarkka, Paunonen, \& Laippala, 1999; Rando, 1993). Vachon and Stylianos (1988) proposed factors such as the timing of support, the amount, from whom support is obtained, and the way support is offered as essential to whether the receiver perceives the guesture to be supportive. These factors have been shown to be relevant to how bereaved people perceive the helpfulness of social support they received (Aoun, Breen, Rumbold, Christian, Same, \& Abel, 2019).

Typically, the most supportive people in times of loss are family and friends (Aoun et al., 2015; Benkel, Wijk, \& Molander, 2009). Bereaved people describe many changes to their social networks following bereavement and may grapple with the loss of other relationships in addition to the death of the deceased (Breen \& O'Connor, 2011; van Der Houwen, Stroebe, Schut, Stroebe, \& Bout, 2010). A spouse is a major source of social support throughout the relationship (Isherwood, King, \& Luszcz, 2012) and therefore the death of one's spouse affects the support that is obtained within one's social network (Utz, Swenson, Caserta, Lund, $\&$ Devries, 2014). One study showed that the receipt of social support is associated with widows' and widowers' adaptation to bereavement (Kim, Kjervik, Belyea, \& Choi, 2011). Another study of widows and widowers, drawing from longitudinal data from representative samples in Germany $(N=1,195)$, Great Britain $(N=562)$, and Australia $(N=298)$, showed an association between social support and subjective wellbeing (Anusic \& Lucas, 2014). However, social networks prior to widowhood did not buffer adaptation to the death of one's spouse. The authors suggested that this finding likely reflects the contribution of spouses to support networks. 
Although social networks can remain stable and supportive before and after bereavement (Utz et al., 2014), bereaved spouses might experience reduced support from close family and friends, loneliness, and social isolation (Stelle \& Uchida, 2004), and may indicate a preference for support from people outside their social networks (Diamond, Llewelyn, Relf, \& Bruce, 2012). A particular challenge experienced by bereaved spouses appears to be the reorientation and re-establishment of themselves within their social networks as an individual and not as part of a couple (Bonanno, Papa, \& O’Neill, 2001; Isherwood et al., 2012; Lowe \& McClement, 2011; Richardson, 2010; Utz et al., 2014; Zettel \& Rook, 2004). As such, this study sought to explore bereaved spouses' social networks, from pre- to post-bereavement, and the support received from these networks.

\section{Methodology}

We used a multiple case study design to uncover rich data that examines a phenomenon through the varied lenses of those who experience the phenomenon (Baxter \& Jack, 2008). Viewing the phenomenon closely through the stories of the participants has the potential to reveal intimate details of their experiences that could otherwise be missed (Pitre, Kushner, Raine, \& Hegadoren, 2013). The multiple case study gathers data from participants and explores the phenomenon of interest as inextricable from the environment in which it occurs (Breen, Wildy, Saggers, Millsteed, \& Raghavendra, 2011).

A constructivist worldview that frames the participants' experience as being inseparable from their connection with others and the community in which they live (Biggerstaff \& Thompson, 2008) underpins this study. Interpretive phenomenological analysis (Smith, 2008) underpinned data collection and analysis, is appropriate for gaining an intimate understanding of the social world of participants, and seeks to reveal participants' meanings as unique to them (Pitre et al., 2013).

\section{Participants}


Participants were sourced from a Facebook group known as "Widows and Widowers United" a group organized and administered by bereaved individuals living in Perth, Australia. The administrator of the group posted a brief advertisement for our study and interested group members were asked to contact the first author. Five adults aged between 43 and 64 years $(M=56.80, S D=8.41)$ were interviewed following the death of their spouse. Time since bereavement ranged from 4 to 6 years $(M=4.60)$.

\section{Materials and Procedure}

The Curtin University Human Research Ethics Committee approved the study. Prior to each interview, participants received written information regarding the project and provided signed informed consent. The first author conducted one-on-one, face-to-face, semistructured interviews with each participant. Semi-structured interviews encourage participants to add further information, reflective of their own experiences (Liamputtong, 2013). Participants were given two diagrams comprising concentric circles, adapted from Bronfenbrenner's (1977) ecological model, to provide visual representations of social networks, pre- and post-bereavement, and explore participants' experiences regarding changes in their social networks and the experiences of social support.

Participants were asked to place their names at the center of each diagram and then map their social networks. On the first diagram, participants mapped their social networks prior to the death of their spouse. On the second, they mapped their current social networks. For both diagrams, participants were asked to indicate the names of individuals and organizations, placing the most important and influential closer to their own names in the center, with those of less importance and influence being placed closer to the edges of the diagrams. Considering social networks on a diagram offers a visual representation of the individual's social sphere (Bronfenbrenner, 1977). The generation of two social network 
maps facilitated much discussion of the similarities and differences between the depiction of social networks over time.

Following the construction of the social network maps, participants were asked to reflect on any changes the experienced in their social networks after the death of their spouse. Questions such as "Could you reflect on any changes in your social networks you noticed in the time after your bereavement?" and "Please tell me of any new friendships you made after your loss?" were asked and included prompts such as "How did changes in your support networks impact your bereavement?" to assist with the gaining of rich data. The interviews were completed either at the university or a mutually agreed upon venue (e.g., participant's home). Participants were interviewed for up to an hour and a half, and audio recorded. At the end of each interview, participants were thanked for their time and received detailed written information about bereavement support services.

\section{Data Analysis and Rigor}

Recordings were transcribed as soon as practicable following each interview. Transcripts were checked against the audio prior to analysis. Data were analyzed using interpretive phenomenological analysis (Smith, 2008). Each case was analyzed individually, with key themes summarized and illustrated by verbatim quotes. Social networks diagrams were examined beside data transcripts as a visual representation of the reorganization of the social networks of participants over time. The first author led the analysis with assistance from the other authors, both of whom are experienced qualitative researchers. Participants were invited to view a summary of findings and asked to provide reflections on themes and clarify the interpretation made by the researchers. Two participants reflected on the findings to support the analysis.

\section{Findings}


The five cases illustrate the experiences of bereaved spouses as they navigate social networks. All names and identifying information are altered to protect the identities of participants and third parties. We provide depictions of the pre- and post-bereavement social networks for two participants, and use codes to indicate a relative (R), friend (F), or work colleague (W).

\section{Adam}

Adam is a 43-year-old man whose wife died six years ago. Adam, his wife, and their children had lived for many years in rural Western Australia before moving to Perth. Prior to his wife's death, his social networks included relatives, close friends, and work colleagues (Figure 1). Adam discussed his life with his wife and children as being typical of family life, with much of his social network involved in the raising of children:

Robert and Rose. They were friends again through the [children's] school network. Umm...Stuart and Samantha the same. They became friends through the school network. Tim and Tania again, same thing, through school. Pamela, again, through the school. And Josh and Jean. Same thing again. Terry is another friend through the school network and the same with Harry and Hillary.

*Insert Figure 1 here*

Post-bereavement, Adam described significant changes in his social network (Figure 1). Adam described receiving instrumental support from those around him at the time of his wife's death (e.g., help with children's school and after-school activities, food parcels during the first months of bereavement) and how over time he was able to re-engage in those tasks for himself:

So, initially, in the beginning it was people bringing meals around, people helping out with getting the kids to and from school sometimes or looking after the kids after school for me. That was probably mainly it. Probably some of the family, the 
relatives, or one of my aunties and uncles and cousin, sort of, helped out with the kids with school holidays and that, looking after them while I was working.

Within the first months, Adam described the withdrawal of social support: "Then over time, the circle sort of dwindled and I suppose that people see that you are on your feet and doing okay". This reduction of connection with close family and friends was reflected upon by Adam as he related his isolation post-loss, and he related how his bereavement as it became a barrier between him and his social networks:

It was probably about two years or so down the track where, you know, you are sitting at home on the weekend, just hearing the kids and the silence. Okay, so, no one is getting in touch and then, you know, you get in touch with people yourself. You are trying to reach out but it sort of feels like maybe a bit of a burden.

Adam also described changes that he made within his own social networks as he attempted to reduce his isolation from others: "I started looking for things to do." Opportunities to relate with others arose as he began to explore interests that he had not engaged with while he had been engaged in married life. Although Adam commented that it took some time to come to terms with, he spoke about engaging himself and his children with social networks vastly different from his life pre-loss as a married person, and the benefit this had for himself as he reoriented himself to single life:

I sort of kept looking and I found a single parents' group and then I joined that and then I started looking around and it was, like, all these different sort of social groups and different activities. So I joined up a few different groups.

Adam reflected on individuals and groups as being important to his navigation of grief. He also spoke about the connections he made through the online support group through which he was recruited. Adam commented about the creation and maintenance of new social 
networks: "I found the widows' group and made a few new friends... So I made a new circle of friends and now it has sort of evolved from there."

\section{Betty}

Betty is a 64-year-old woman whose husband died four years ago. Betty was married to her husband for her entire adult life and continues to live in the house she shared with her husband. Betty recalled active participation in social events before the death of her husband: "I had three Saturdays where I had about 15 or 16 people for supper each time from our old friends". However, Betty described the withdrawal of support from her network marked her life post-loss: "Friends are always very good initially; down the track, you don't see them that much."

Betty explained that she found it difficult to engage with others who did not react in expected ways and reflected that the support of others was a source of disappointment to her and affected her grieving:

I have a couple of friends that have always kept in touch. One is sick now, but the other one, I pop into hers, she pops into mine but never says, "We're having eggs on toast, do you want to come around?" or "We're going for a drive, do you want to come with us?" They just don't think about it. Look, I'm happy with an egg, for God's sake. I'm happy with baked beans. Just come over. You know?

Betty commented that her engagement with support groups was instrumental in her grief because it was in this way that she engaged with others who had experienced spousal bereavement, including her connection with the Facebook group through which she was recruited:

It is only this year perhaps that I have vented, put something on there. So, for the last three years, I wouldn't have. I would just read it all and I would cry when I read it and, so I wouldn't say they have really been there as such. 
Betty stated that her connection with other, community-based bereavement groups had been more important in terms of helping her navigate the challenges of bereavement, especially because she was able to engage with reciprocal support for others who were experiencing similar life stressors:

But we're basically there, I suppose, to make the numbers to be supportive. I have actually had five of them here for an afternoon tea. And I thought it was just getting together and having a coffee at a café, talking, that would have been great. I don't...it's not that I don't need because I still cry when I talk about it but I didn't want to go to have counselling as such.

For Betty, access to group-based support from others in a similar situation was preferable to one-on-one counseling:

I went to two counselors. I had, I don't know, 14 free visits. I didn't like the counselors, nothing against them [but] I prefer to be in a group. I like to talk to people. I like to see what they say, you know.

\section{Cathy}

Cathy is a 55-year-old woman whose husband died five years ago. Cathy reflected on the changes in her social networks pre- to post-loss. Cathy discussed her bereavement experience as an abrupt cut-off from previous social networks and isolation that she commented as taking a long time to work through. Until she reached out for a bereavement group, her greatest support had been her adult children; others who she thought would be supportive were "unavailable."

Cathy stated that she was severely affected by this change in her social networks and her grief trajectory compromised by the poverty of social interaction caused by her husband's illness and death. Specific to her difficulties was the withdrawal of support by family and extended family: "In those months afterwards when family should have been, they were 
gone. I don’t know. They just didn’t keep in touch." Cathy said that she was unable to connect with social networks outside of her dealings with her children until she connected with the Facebook group through which she was recruited. Cathy said:

I got more support from writing on the "Widows and Widowers" site and they were super supportive of and helpful with information that you need to know, that widows need to know but don't know. It just felt like I belonged there from day one.

Further, Cathy commented that she was able to connect to other community groups through her positive experience of this Facebook group. Cathy described discovering greater internal resources and benefiting from the modeling of functional behavior by others in the group, which encouraged her to rediscover herself, reengage with her own social world, and explore new social networks:

It's something to look forward to. I love going there. The people there are generous.

They're creative. They're people that I have never been around in my life so... [I have discovered] a completely different world than I had lived in for 28 years ... It's starting to make me feel proud of myself but it's taken me a long time to get to this stage where I think “well, I'm not as good as them but I'm good”. It's good now. Yeah, I [pause] I mean, I like my life now. I like my painting.

\section{Dianne}

Dianne is a 60-year-old woman whose husband died four years ago. Dianne illustrated changes in her social networks from pre- to post-loss. Dianne discussed her social networks prior to her loss and the activities in which she and her husband would engage:

We would have the kids over for meals. We would have family barbecues down the park. We would go out on my sister and brother-in-law's boat and just hang out. And I was working part-time and then we would do things, mostly with the kids. They would come over for meals or we would go out, you know. We never got all the kids 
together at once-you could see three on Wednesday and then it might be, you know, another two that we could catch up with on the weekend because they all had other things on.

Although they had a rich social life that involved family, Dianne commented that she and her spouse rarely interacted in community social groups and activities preferring their own company and interests:

No tennis groups, no caravanning groups, or camping. We just did it ourselves and by the time we were finished with work and kids, we didn't really want anybody else. We just wanted to be together and do stuff together.

Dianne commented that her immediate family was very supportive of her grieving process and she of theirs:

My support network had been grieving with me, I guess. So, the kids, you know, they lost a dad. They didn't lose a partner but they still lost a dad. My mum lost a son-inlaw. My sister lost a brother-in-law. You know ... umm... they were very close. They were all close.

Despite family support, Dianne discussed the intensity of her grief reaction and her inability to connect with others or engage with the social world for many months post-loss: Because you feel like you are the only person in the whole world that is going through, you know, this loss...feeling of loss. Cognitively, if that is the right word, you know, you sort of know that you are not. People die all the time but, at the time, you do feel like nobody understands you are completely alone. And everyone is just living their lives and doing normal stuff. But, yeah, you just feel completely [long pause] separate to anything that is going on. Everything around you is just surreal and doesn't make sense. [So] I pushed them away. I pushed everyone away a bit... and there really weren't that many people other than our family any way but the ones that 
we did see, like the few work colleagues that we did catch up with and my cousinsespecially the two girls, because I have got a few cousins but they were my closest-I pushed them away. I didn't want to see them.

Dianne stated that it had been the connection with the Facebook group through which she was recruited that had been instrumental in helping her develop new friendships with other widows and widowers that allowed her to re-experience the social world:

The Widows and Widowers were very important. They were very, very important and then, consequently, I started to make some good friends through there. I got there and that's when I started to make connections with, umm, people that really had the most profound impact on my recovery, I guess. I connected with these people and some of them I still have a strong connection with... people that understand. I think that's the most important thing. Because they are sort of going through the same sort of thing... To sort of make me feel less isolated. I think that is the key word.

Dianne reflected on how her social networks have changed over the years since her bereavement and how she has created new friendships based on her connections with other widows and widowers:

Well, my social connections are now completely different. I didn't have a great deal of social connections anyway when my husband and I were together for that 15 years. I am a lot busier socially now than I was and so... umm... I Jenny and Corinne now, they are widows and we will catch up whenever we can. So, you know, and my friends... my special, close friends are widows.

\section{Eddy}

Eddy is a 62-year-old woman whose husband died four years ago. Eddy's social networks were intimately entwined with her husband's prior to his death, with few independent networks. This lack of independent social functioning is reflected in her 
depictions of her pre- and post-loss social networks (Figure 2). Eddy reflected on her social networks before her husband died, and the relationships that she had with others that involved her as part of a married couple. Eddy recalled that much of her social network at that time was formed around nuclear family functioning, raising children, and continued interaction with extended family. Eddy reflected that much of her pre-loss support reflected the raising of children:

These [sporting clubs] were what the kids were pretty much in and what Evan became involved in... and they became, that was our life. You know... for the first 10, 12, 15 years of our [married] lives were always at those places. A little bit of social but mainly, mainly just the sport and group.

Eddy's reflections on her social networks after her bereavement are indicative of her close relationship with her spouse and the difficulties she experienced renegotiating her social networks without his continued support. Eddy experienced a loss of connection to many of her existing networks and reflected on in her interview:

Jane and Joe, obviously, they completely left the scene and the picture. Completely. They just weren't there. Brian was Evan's best friend and a good friend to me, I thought, but he just wasn't there. Couldn't be there, wouldn't be there. And Alan did the same thing. Just left the scene, the same scenario ... That was probably the most hurtful thing I have been through, apart from losing Evan, was to be, not betrayed, but let down.

\section{*Insert Figure 2 here*}

Although Eddy felt let down by some people in her social network, she also expressed surprise about those who were supportive and to whom she could turn:

He would just call in out of the blue. He never used to, so, all of a sudden, he was calling in to see me, to see if I was alright, which was really surprising ... I know I 
could turn to him, in a heartbeat. I think he wanted to be emotionally supportive but I didn't have him on that level prior to anything happening [with Evan].

Further, Eddy spoke about an organization within which her spouse was embedded that provided considerable support for her and her family at the time of her bereavement:

Soccer Club - they came to the party. They were there in droves. They supported me on an emotional level. A couple actually spoke at his funeral. At the hospital—God, they were there en masse, you know, in the ICU. Evan's best friend couldn't be there but we had half of the soccer club wanting to see him ... Probably over 12 months after Evan died, they were there in any shape or form. That was just the kind of club they were.

Eddy reflected on new friendships that she made post-loss with individuals she met who were undergoing similar life stressors. She commented on the kinds of support garnered from these friendships as being influential in her negotiating social networks after bereavement:

The beauty of the new friendships is that it is based, well, because of where the friendships came from, it is a free-for-all. No matter what you are thinking and how you are feeling, we can say it, straight away. There is no awkwardness. There is no uncomfortable-ness. There is just, you can say it, because they are going through similar [things]. There is a common theme and it is a comforting common theme. It is comfortable to know that I can go and have a cup of coffee with Trish or I can just give her a call and say "I'm feeling not so good today".

\section{Discussion}

Through the qualitative exploration of five case studies, we illustrated the changes that occurred in social networks by bereaved spouses as they navigated the loss. Although each participant described their grief experiences as unique, and each spoke about the 
individual way they negotiated bereavement (Isherwood et al., 2012; Lobb et al., 2010; Schnittger et al., 2012), a common theme was the inevitable change of roles of other individuals and groups close to the bereaved as impacted by the death of the spouse. Some participants indicated building stronger relationships with family and friends (e.g., Eddy and Dianne) and others indicated a loss of intimate social networks (e.g., Cathy, Betty, and Adam). Participants described seeking community groups, new arenas for social interaction, and connection with likeminded others to support the restoration of their social networks over time.

The participants' experiences of grief and the renegotiation of social networks reflect the difficult task of finding support as an individual when their lives had been intricately enmeshed with their spouses for many years. They described the difficulty of social relationships changing or ending, and the disappointment experienced when friends and family could not support them in their time of need. Importantly, the death of a spouse precipitated the dramatic reorganization of social networks to incorporate this crisis and adapt to a new life. These findings build upon those previously reported by researchers in this area (Breen, \& O'Connor, 2011; Lobb et al., 2010; Vachon et al., 1982).

The perception of support from social networks is a significant factor toward psychological growth for bereaved individuals (Blackburn, \& Dwyer, 2017; Burke \& Neimeyer, 2013; Lobb et al., 2010); it is also important as a key factor that may be altered to better assist the grieving process (Logan et al., 2018). However, the particpants emphaized the importance of the connection with others who were also widowed was highlighted by each participant as necessary for emotional support. Participants in this study described friendships made through a mutual bereavement support group as instrumental in each individual's sense of inclusion once more in the social world. The need for connection with others who have similar experiences is also emphasized in other studies of bereaved people 
(Breen \& O’Connor, 2010, 2011; Breen et al., 2017; Breen, Karangoda, Kane, Howting, \& Aoun, 2018; Diamond et al., 2012; Kim et al., 2011; Vachon \& Stylianos, 1988).

The finding that these connections may be facilitated online aligns with research showing that Internet-based peer support is growing and can be promote accessibility to support (Bartone, Bartone, Violanti, \& Galeno, 2019). Interestingly, one systematic review of peer support for the bereaved showed that studies of Internet-based peer support are focused on bereaved mothers and those bereaved by suicide; none of the reviewed studies were specific to Internet-based peer support for widows/widowers (Barton et al., 2019). The finding that connections with other widows and widowers assisted social re-engagement may inform health professionals to assist grieving spouses. For example, bereaved people might benefit from guidance concerning connecting with others who have a shared experience (whether online, offline, or both), as well as how to harness existing social networks to optimize received support.

Drawing from an ecological model (Bronfenbrenner, 1977), the inclusion of visual representations of social networks, pre- and post-bereavement, alongside semi-structured interviews, meant that we were able to develop a holistic picture of the subjective experiences of each participant. However, participants were sourced from a group that specifically supported the bereavement experience of grieving spouses, and it is likely that others who do not utilize this form of social network could relate a different trajectory for the navigation of social networks post-loss. Participants were drawn from those who had experienced bereavement for some time in order to accommodate the reorientation of their social networks. Although the passage of time affects the accuracy of information that is recalled in an interview (Williams, Woodby, Bailey, \& Burgio, 2008), we were not attempting to document the objective truth; instead, we were interested in the participants lived experiences of their social networks over time. Our design means we could not report a response rate or 
determine if those who volunteered to participate were representative of widows/widowers.

One recent study showed that family carers who volunteer for a research interview are younger and report less grief than those who do not (Breen, Johnson, O’Connor, Howting, \& Aoun, 2020). A future study employing a longitudinal design, and with a larger and more diverse sample, is warranted to examine the changes of social networks over time.

\section{Declaration of Conflicting Interests}

The authors declare no potential conflicts of interest with respect to the research, authorship, and/or publication of this article.

\section{Funding}

The authors receive no financial support for the research, authorship, and/or publication of this article.

\section{Author Biographies}

Brigid Morrigan completed her Master of Psychology (Counselling Psychology) at Curtin University.

Sharon Keesing is an academic and occupational therapist. Her research interests include palliative care, cancer rehabilitation, and the impact of terminal disease on carers and family members.

Lauren J. Breen is an associate professor in psychology. She has been conducting research focussed on understanding and improving experiences of serious illness and bereavement for 20 years. 


\section{References}

Anusic, I., \& Lucas, R. (2014). Do social relationships buffer the effects of widowhood? A prospective study of adaptation to the loss of a spouse. Journal of Personality, 82, 367-378.

Aoun, S. M., Breen, L. J., Howting, D., Rumbold, B., McNamara, B., \& Hegney, D. (2015). Who needs bereavement support? A population based survey of bereavement risk and support need. PLoS ONE, 10(3): e0121101.

Aoun, S. M., Breen, L. J., Rumbold, B., Christian, K. M., Same, A., \& Abel, J. (2019). Matching response to need: What makes social networks fit for providing bereavement support? PloSONE, 14(3), e0213367.

Aoun, S. M., Breen, L. J., White, I., Rumbold, B., \& Kellehear, A. (2018). What sources of bereavement support do bereaved people perceive to be helpful and why? Empirical evidence for the Compassionate Communities approach. Palliative Medicine, 32, $1378-1388$.

Bartone, P. T., Bartone, J., V., Violanti, J. M., \& Galeno, Z. M. (2019). Peer support services for bereaved survivors: A systematic review. Omega: Journal of Dealth and Dying, $80,137-166$.

Baxter, P., \& Jack, S. (2008). Qualitative case study methodology: Study design and implementation for novice researchers. Qualitative Report, 13, 544-559.

Benkel, I., Wijk, H., \& Molander, U. (2009). Family and friends provide most social support for the bereaved. Palliative Medicine, 23, 141-149.

Biggerstaff, D., \& Thompson, A. (2008). Interpretative phenomenological analysis (IPA): A qualitative methodology of choice in healthcare research. Qualitative Research in Psychology, 5, 214-224. 
Bonanno, G. A., Papa, A., \& O'Neill, K. (2001). Loss and human resilience. Applied and Preventive Psychology, 10(3), 193-206.

Blackburn, P., \& Dwyer, K. (2017). A bereavement common assessment framework in palliative care: Informing practice, transforming care. American Journal of Hospice and Palliative Care, 34, 677-684.

Breen, L., Aoun, S., Rumbold, B., McNamara, B., Howting, D., \& Mancini, V. (2017). Building community capacity in bereavement support: Lessons learnt from bereaved caregivers. American Journal of Hospice and Palliative Medicine, 34, 275-281.

Breen, L. J., Johnson, A. R., O’Connor, M., Howting, D., \& Aoun, S. M. (2020). Challenges in palliative care research on family caregivers: Who volunteers for interviews? Journal of Palliative Medicine. https://doi.org/10.1089/jpm.2019.0672

Breen, L. J., Karangoda, M. D., Kane, R. T., Howting, D. A., \& Aoun, S. M. (2018). Differences in meanings made according to prolonged grief symptomatology. Death Studies, 42, 69-78.

Breen, L. J., Kawashima, D., Joy, K., Cadell, S., Roth, D., Chow, A., \& Macdonald, M. E. (2020). Grief literacy: A call to action for compassionate communities. Death Studies. https://doi.org/10.1080/07481187.2020.1739780

Breen, L. J., \& O'Connor, M. (2010). Acts of resistance: Breaking the silence of grief following traffic crash fatalities. Death Studies, 34, 30-53.

Breen, L., \& O'Connor, M. (2011). Family and social networks after bereavement: Experiences of support, change, and isolation. Journal of Family Therapy, 33, 98-120. Breen, L. J., Szylit, R, Gilbert, K. R., Macpherson, C., Murphy, I., Nadeau, J. W., Reis e Silva, D., Wiegand, D. L., and the International Work Group on Death, Dying and Bereavement. (2019). Invitation to grief in the family context. Death Studies, 43, 173182. 
Breen, L., Wildy, H., Saggers, S., Millsteed, J., \& Raghavendra, P. (2011). In search of wellness: allied health professionals' understandings of wellness in childhood disability services. Disability and Rehabilitation, 33, 862-871.

Bronfenbrenner, U. (1977). Toward an experimental ecology of human development. American Psychologist, 32, 513-531.

Burke, L. A, \& Neimeyer, R. A. (2013). Protective risk factors for complicated grief: a review of the empirical literature. In M. Stroebe, H. Schut, \& J. van den Bout (Eds.), Complicated grief: Scientific foundations for health care professionals (pp. 145-161). New York: Routledge.

Center for the Advancement of Health. (2004). Report on bereavement and grief research. Death Studies, 28, 491-575.

Diamond, H., Llewelyn, S., Relf, M., \& Bruce, C. (2012). Helpful aspects of bereavement support for adults following an expected death: Volunteers' and bereaved people's perspectives. Death Studies, 36, 541-564.

Isherwood, L., King, D., \& Luszcz, M. A. (2012). A longitudinal analysis of social engagement in late-life widowhood. International Journal of Aging and Human Development, 74(3), 211-229.

Kaunonen, M., Tarkka, M.-T., Paunonen, M., \& Laippala, P. (1999). Grief and social support after the death of a spouse. Journal of Advanced Nursing, 30, 1304-1311.

Kim, S. H., Kjervik, D., Belyea, M., \& Choi, E. S. (2011). Personal strength and finding meaning in conjugally bereaved older adults: A four-year prospective analysis. Death Studies, 35, 197-218.

Liamputtong, P. (2013). Qualitative research methods (4th ed.). South Melbourne, Victoria: Oxford University Press Australia. 
Lobb, E., Kristjanson, L., Aoun, S., Monterosso, L., Halkett, G., \& Davies, A. (2010). Predictors of complicated grief: A systematic review of empirical studies. Death Studies, 34, 673-698.

Logan, E. L., Thornton, J. A., \& Breen, L. J. (2018). What determines supportive behaviours following bereavement? A systematic review and call to action. Death Studies, 42, 104-114.

Lowe, M., \& McClement, S. (2011). Spousal bereavement: The lived experience of young Canadian widows. Omega: Journal of Dealth and Dying, 62, 127-148.

Pitre, N. Y., Kushner, K. E., Raine, K. D., \& Hegadoren, K. M. (2013). Critical feminist narrative inquiry: Advancing knowledge through double-hermeneutic narrative analysis. Advances in Nursing Science, 36, 118-132.

Rando, T. A. (1993). Treatment of complicated mourning. Champaign, IL: Research Press.

Richardson, V. (2010). Length of caregiving and well-being among older widowers: Implications for the Dual Process Model of bereavement. Omega: Journal of Death and Dying, 61, 333-356.

Schnittger, R. I. B., Wherton, J., Prendergast, D., \& Lawlor, B. A. (2012). Risk factors and mediating pathways of loneliness and social support in community-dwelling older adults. Aging and Mental Health, 16, 335-346.

Smith, J. A. (2008). Qualitative psychology: A practical gude to research methods. London: Sage.

Stelle, C., \& Uchida, M. (2004). The stability and change in the social support networks of widowers following spousal bereavement. Journal of Men's Studies, 13, 85-105.

Thompson, N., Allan, J., Caverhill, P. A., Cox, G. R., Davies, B., Doka, K., ... \& Wittkowski, J. (2016). The case for a sociology of dying, death, and bereavement. Death Studies, 40, 172-181. 
Utz, R. L., Swenson, K. L., Caserta, M., Lund, D., \& Devries, B. (2014). Feeling lonely versus being alone: Loneliness and social support among recently bereaved persons. The Journals of Gerontology. Series B, Psychological Sciences and Social Sciences, 69(1), 85 .

Vachon, M. L., Sheldon, A. R., Lancee, W. J., Lyall, W. A., Rogers, J., \& Freeman, S. J. (1982). Correlates of enduring distress patterns following bereavement: Social network, life situation and personality. Psychological Medicine, 12(4), 783-788.

Vachon, M. L., \& Stylianos, S. (1988). The role of social support in bereavement. The Journal of Social Issues, 44(3), 175-190.

van Der Houwen, K., Stroebe, M., Schut, H., Stroebe, W., \& van den Bout, J. (2010). Mediating processes in bereavement: The role of rumination, threatening grief interpretations, and deliberate grief avoidance. Social Science and Medicine, 71, 1669-1676.

Williams, B. R., Woodby, L. L., Bailey, F. A., \& Burgio, K. L. (2008). Identifying and responding to ethical and methodological issues in after-death interviews with nextof-kin. Death Studies, 32, 197-236.

Zettel, L., \& Rook, K. S. (2004). Substitution and compensation in the social networks of older widowed women. Psychological Aging, 19, 433-443. 

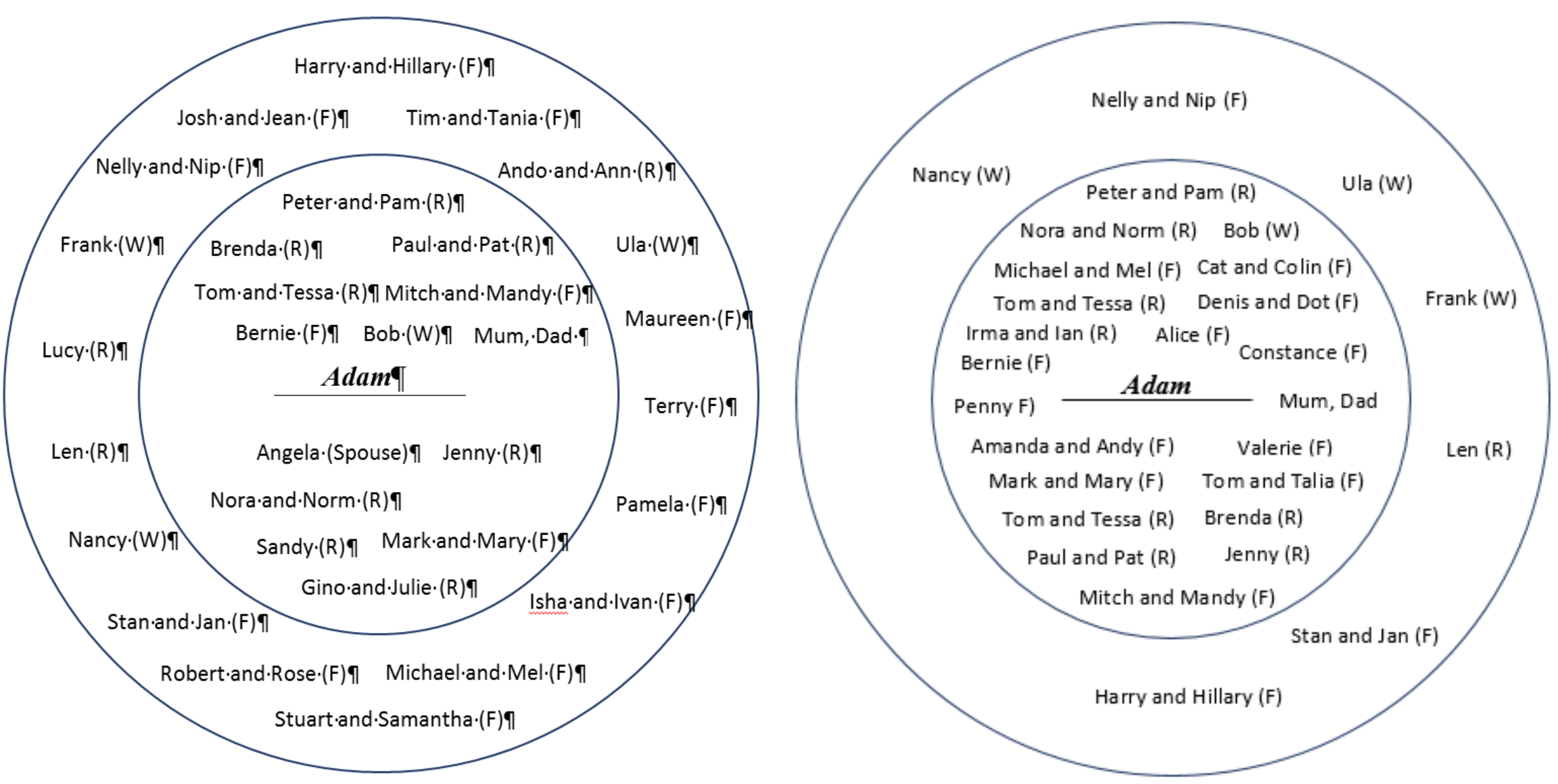

Figure 1. Social network maps, pre- and post-loss, for Adam. $\mathrm{R}=$ relative, $\mathrm{F}=$ friend, $\mathrm{W}=$ work colleague. 


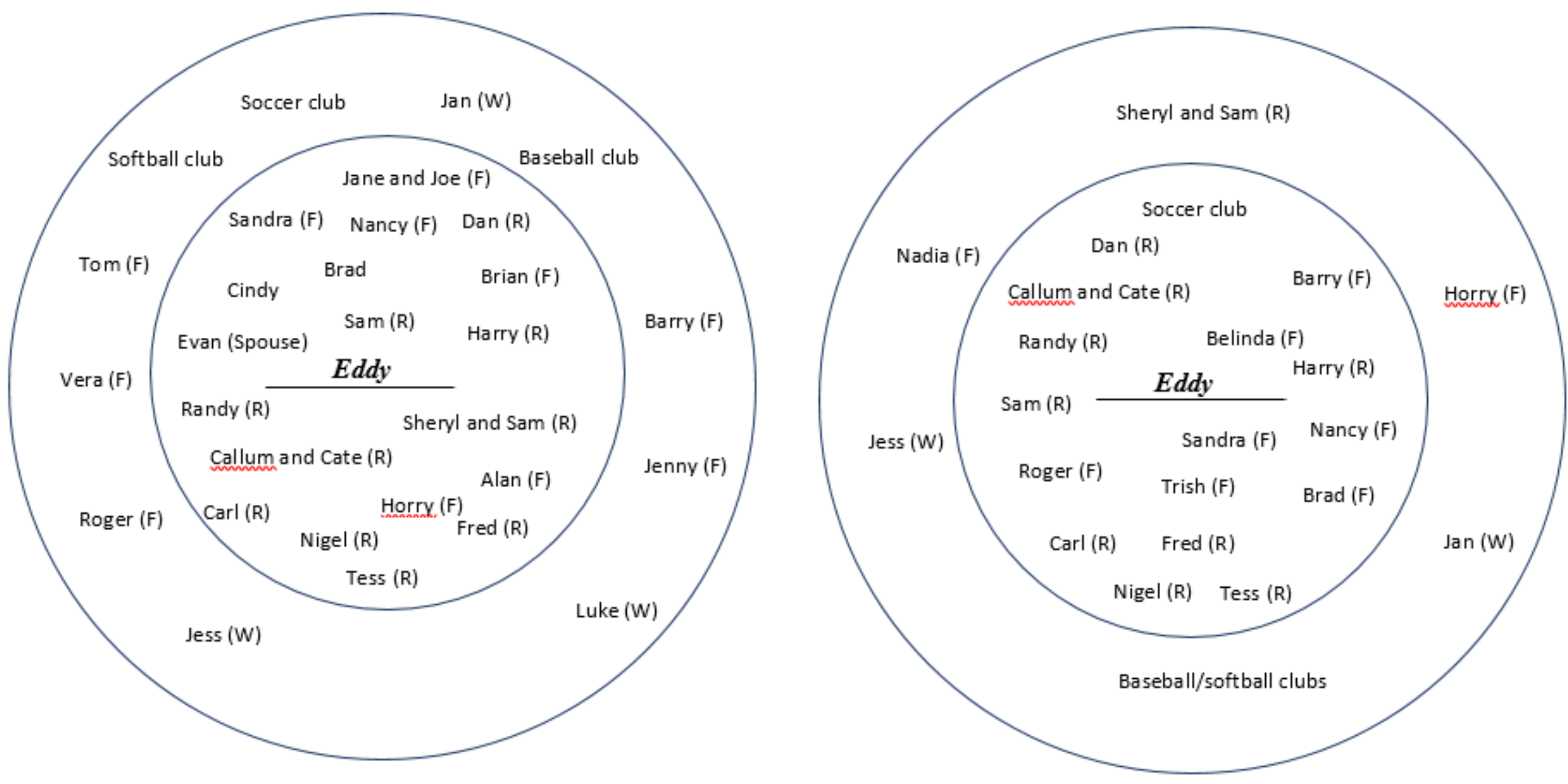

Figure 2. Social network maps, pre- and post-loss, for Eddy. $\mathrm{R}=$ relative, $\mathrm{F}=$ friend, $\mathrm{W}=$ work colleague. 